\title{
Unusual presentation of pheochromocytoma: thirteen years of anxiety requiring psychiatric treatment
}

\author{
Catherine Alguire', Jessica Chbat', Isabelle Forest ${ }^{2}$, Ariane Godbout ${ }^{1}$ \\ and Isabelle Bourdeau'
}

1Division of Endocrinology, Department of Medicine and Research Center (CRCHUM), Centre hospitalier de I'Université de Montréal, Montreal, Québec, Canada and 'Department of Psychiatry, Centre hospitalier Pierre-Le Gardeur, Terrebonne, Québec, Canada

\author{
Correspondence \\ should be addressed \\ to I Bourdeau \\ Email \\ isabelle.bourdeau@ \\ umontreal.ca
}

\begin{abstract}
Summary
Pheochromocytoma is a rare tumor of the adrenal gland. It often presents with the classic triad of headache, palpitations and generalized sweating. Although not described as a typical symptom of pheochromocytoma, anxiety is the fourth most common symptom reported by patients suffering of pheochromocytoma. We report the case of a 64 year old man who had severe anxiety and panic disorder as presenting symptoms of pheochromocytoma. After 13 years of psychiatric follow-up, the patient was diagnosed with malignant pheochromocytoma. After surgical resection of his pheochromocytoma and his hepatic metastases, the major panic attacks completely disappeared, the anxiety symptoms improved significantly and the psychiatric medications were stopped except for a very low maintenance dose of venlafaxine. We found in our cohort of 160 patients with pheochromocytoma 2 others cases of apparently benign tumors with severe anxiety that resolved after pheochromocytoma resection. These cases highlight that pheochromocytoma should be included in the differential diagnosis of refractory anxiety disorder.
\end{abstract}

\section{Learning points:}

- Anxiety and panic disorder may be the main presenting symptoms of pheochromocytoma.

- The diagnosis of pheochromocytoma should be excluded in cases of long-term panic disorder refractory to medications since the anxiety may be secondary to a catecholamine-secreting tumor.

- Surgical treatment of pheochromocytoma leads to significant improvement of anxiety disorders.

\section{Background}

Pheochromocytoma is a rare catecholamine-producing tumor originating from the chromaffin cells of the medulla, the central part of the adrenal gland (1). Its annual incidence is estimated to be about 0.8 per 100000 person-years. The prevalence of malignant pheochromocytoma is approximately $10-17 \%$ with a definition of malignancy being the presence of metastases in nonchromaffin tissue (2). Some patients present with typical symptoms, but some do not have the classic triad.
We report the case of a patient who had severe refractory anxiety as a presenting symptom of pheochromocytoma. After 13 years of psychiatric follow-up, the patient was finally diagnosed with malignant pheochromocytoma. Atypical and refractory cases of severe anxiety require to exclude the diagnosis of pheochromocytoma to avoid delayed diagnosis that may lead to larger tumors and the presence of metastases, which are associated with more morbidity and mortality. 


\section{Case presentation}

A 64-year-old man consulted his physician in the spring of 2015 for new-onset diarrhea. His personal medical history was mostly significant for depression and anxiety disorder; in 2011, he was even hospitalized for two months for a depressive episode. He was then prone to waking up in the middle of the night, a few times per week or month, with severe anxiety, vomiting, tremor and palpitations. The symptoms improved with anxiety treatment, and his psychiatrist was able to taper down the medication to a treatment similar to those suggested by the current treatment guidelines for generalized anxiety disorder. He also had a 5-year history of hypertension, dyslipidemia and benign prostatic hyperplasia. The patient's medication included clonazepam $0.5 \mathrm{mg} \mathrm{HS}$, venlafaxine $187.5 \mathrm{mg} /$ day and quetiapine XR $25 \mathrm{mg} /$ day. He was also taking daily doses of ezetimibe, amlodipine, pravastatin, esomeprazole, mirabegron, propranolol and tamsulosin. No family history of pheochromocytoma, paraganglioma or unexplained sudden death was reported.

Because of the new-onset diarrhea, the patient's family doctor requested a CT scan, which demonstrated a voluminous left adrenal mass of $18.2 \times 16.3 \mathrm{~cm}$ with two liver lesions of 2.2 and $2.5 \mathrm{~cm}$, suspicious of metastases. MRI confirmed the adrenal mass and detected a third hepatic lesion of $0.5 \mathrm{~cm}$ (Fig. 1A).

\section{Investigation and treatment}

Results of initial laboratory evaluation of the adrenal lesion demonstrated very high 24-h urine catecholamines with normetanephrines of 235,382 $\mathrm{nmol} /$ day (Normal value $(\mathrm{NV})<240$ ), metanephrines of $97,492 \mathrm{nmol} /$ day $(\mathrm{NV}<275)$, dopamine of $7745 \mathrm{nmol} /$ day $(\mathrm{NV}<2570)$, epinephrine of $2710 \mathrm{nmol} /$ day $(\mathrm{NV}<110)$ and norepinephrine of $1183 \mathrm{nmol} / \mathrm{day}(\mathrm{NV}<440)$. The plasma free normetanephrine was $663 \mathrm{nmol} / \mathrm{L}(\mathrm{NV}<1.20)$ while free metanephrine was $156 \mathrm{nmol} / \mathrm{L}(\mathrm{NV}<0.48)$, thus confirming the diagnosis of pheochromocytoma. A (18F)-fluorodeoxyglucose-positron emission tomography/computed tomography (PET/CT) showed uptake of the adrenal mass with a standardized uptake value $\left(\mathrm{SUV}_{\max }\right)$ of 7.8 (Fig. 1B). There was no hepatic uptake. The patient was scheduled for urgent left adrenalectomy. The pathology report confirmed the diagnosis of pheochromocytoma with lymphovascular invasion. The urine norepinephrine and normetanephrine levels and the plasma free normetanephrines and metanephrines remained slightly elevated following the adrenalectomy (Table 1). A post-operative meta-iodobenzylguanidine (MIBG) scan confirmed the uptake of two liver metastases. The patient underwent partial hepatectomy a few weeks later to remove the hepatic lesions which were all confirmed to be pheochromocytoma metastases.

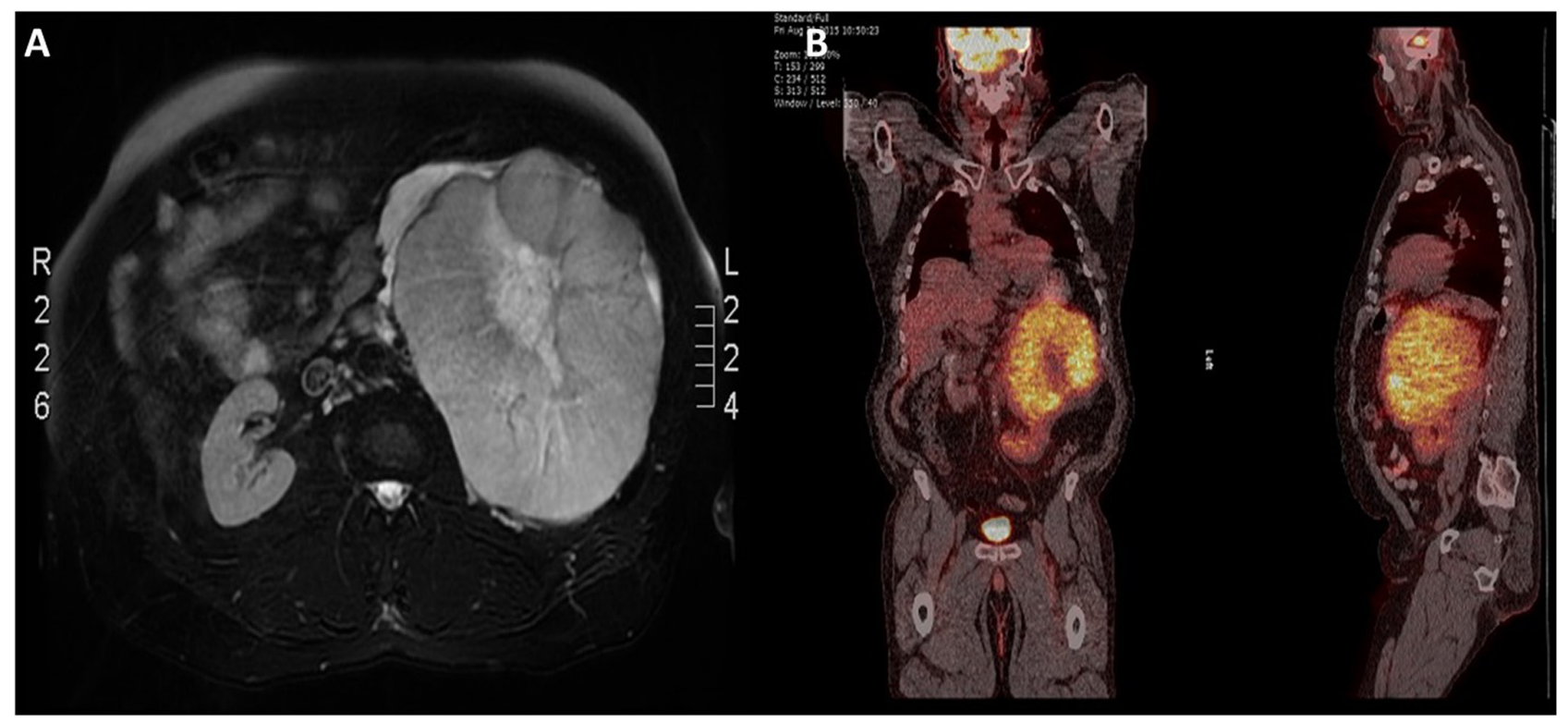

Figure 1

(A) Magnetic resonance imaging (MRI) demonstrates a left adrenal mass of $18.2 \times 16.3 \mathrm{~cm}$ and two liver lesions of 2.2 and $2.5 \mathrm{~cm}$. (B) Fluorodeoxyglucose positron emission tomography (FDG-PET)/computerized tomography (CT) shows prominent uptake of the left adrenal mass with a standardized uptake value $\left(S_{U} V_{\text {max }}\right)$ of 7.8. The two hepatic lesions show SUV max only slightly more elevated than the physiologic uptake of the liver. 
Table 1 Values of urine and plasma catecholamines at diagnosis, after adrenalectomy and after hepatectomy.

\begin{tabular}{|c|c|}
\hline & $\begin{array}{c}\text { At diagnosis } \\
(2015-06-12)\end{array}$ \\
\hline Urine normetanephrine & 235,382 \\
\hline Urine metanephrine & 97,492 \\
\hline Urine dopamine & 7745 \\
\hline Urine norepinephrine & 1183 \\
\hline Urine epinephrine & 2710 \\
\hline Plasma free normetanephrine & 663 \\
\hline Plasma free metanephrine & 156 \\
\hline
\end{tabular}

\begin{tabular}{c}
$\begin{array}{c}\text { After adrenalectomy } \\
(2015-09-04)\end{array}$ \\
\hline 319 \\
156 \\
1017 \\
452 \\
33 \\
1.31 \\
0.61
\end{tabular}

\begin{tabular}{c}
\hline Normal values \\
\hline$<240 \mathrm{nmol} / \mathrm{day}$ \\
$<275 \mathrm{nmol} / \mathrm{day}$ \\
$<2570 \mathrm{nmol} / \mathrm{day}$ \\
$<440 \mathrm{nmol} / \mathrm{day}$ \\
$<110 \mathrm{nmol} / \mathrm{day}$ \\
$<1.20 \mathrm{nmol} / \mathrm{L}$ \\
$<0.48 \mathrm{nmol} / \mathrm{L}$
\end{tabular}

After hepatectomy, urine catecholamines and plasma free normetanephrines and metanephrines levels were within normal values (Table 1). Following genetic counseling, the patient consented for genetic analysis for paraganglioma-pheochromocytoma-related genes. A panel analyzing 14 genes (VHL, RET, NF1, SDHD, SDHB, SDHC, SDHA/SDHAF2, TMEM127, MAX, FH, EGLN1, KIF1B, MEN1) (Invitae, San Francisco, CA, USA) was performed on leucocyte DNA of the patient and did not identify any mutations.

After surgery, the patient reported that his panic attack episodes were completely resolved. The quetiapine and clonazepam were successfully stopped; however, venlafaxine was continued at a lower maintenance dose of $75 \mathrm{mg}$ per day instead of $187.5 \mathrm{mg}$ per day. It was strongly suspected that before adrenalectomy, the patient's anxiety symptoms were most probably intensified by the discharge of catecholamines secondary to pheochromocytoma. It is of note that many doctors had seen the patient by the time the diagnosis was made.

\section{Severe anxiety in our large cohort of pheochromocytomas}

We analyzed retrospectively our cohort of 160 patients at Centre hospitalier de l'Université de Montréal with pheochromocytoma. Two other cases of severe anxiety with drastic improvement of psychiatric symptoms postoperatively were identified. They are described briefly below.

\section{Patient 1}

A 46-year-old female with a history of 6 years of severe panic attacks and anxiety was investigated for diarrhea and hypertension. She was found to have a $3.2 \times 3.5 \mathrm{~cm}$ right adrenal mass on MRI performed in the context of her abdominal symptoms such as for the patient described earlier. Her 24-h urine catecholamines were elevated with norepinephrine of $783 \mathrm{nmol} /$ day $(\mathrm{NV}<440)$ and epinephrine of $1501 \mathrm{nmol} /$ day $(\mathrm{NV}<110)$, thus confirming the diagnosis of pheochromocytoma. Urinary catecholamines were normalized and panic attacks disappeared after right adrenalectomy.

\section{Patient 2}

A 30-year-old female with a long-standing history of severe anxiety requiring psychiatric hospitalization was investigated in the context of severe hypertension and anxiety. A right adrenal mass of $4.1 \times 3.6 \mathrm{~cm}$ was incidentally found on MRI. Her hormonal work-up revealed elevated 24-h urine catecholamines with norepinephrine of $17 \quad 254 \mathrm{nmol} /$ day $\quad(\mathrm{NV}<440)$, normetanephrines of $11577 \mathrm{nmol} /$ day $(\mathrm{NV}<240)$ and epinephrine of $330 \mathrm{nmol} /$ day $(\mathrm{NV}<110)$. The plasma free normetanephrine was $27.2 \mathrm{nmol} / \mathrm{L}(\mathrm{NV}<1.20)$ while free metanephrine was $1.48 \mathrm{nmol} / \mathrm{L} \quad(\mathrm{NV}<0.48)$ thus confirming the diagnosis of pheochromocytoma. Her psychiatric disease completely resolved following right adrenalectomy, and a normalization of both urinary and plasmatic normetanephrines and metanephrines was noted. Genetic testing was offered to the patient for the following genes: $S D H B, S D H C, S D H A F 2, V H L, N F 1$ and $R E T$. No genetic mutations were found.

\section{Discussion}

Pheochromocytomas are rare catecholamine-producing neuroendocrine tumors originating from adrenomedullary chromaffin cells with an incidence estimated to be less than 1 per 300000 persons per year. More than $40 \%$ of patients with pheochromocytomas harbor a germline mutation in one of the known susceptibility genes (3). According to the 2014 Endocrine Society Guidelines, all patients with pheochromocytoma or paraganglioma 
should be offered genetic testing (1). Our patients consented for genetic analysis of pheochromocytomarelated genes but no germline disease-causing mutations were identified.

The classic triad of symptoms in a patient with pheochromocytoma includes palpitations, headache and generalized sweating (4). The symptoms may occur in a paroxysmal manner and are caused by the high circulating catecholamine levels produced by the tumor. Although episodic hypertension, headache and sweating raises suspicion for pheochromocytoma, a large number of patients experience much more subtle symptoms, making the diagnosis even more challenging to the physician. It is exactly the case with the patient we report here since the diagnosis of pheochromocytoma was delayed, even though he was evaluated several times by different doctors for his various symptoms: emergency room doctor, urologist, internist, psychiatrists and family doctor. Less common symptoms and signs are numerous and include visual disturbance, cardiomyopathy and psychiatric disorder. Anxiety is nevertheless the fourth most common symptom of pheochromocytoma after the classic triad of headache, sweating and palpitations and is estimated to occur in about $30 \%$ of patients. In the patient presented earlier, the initial symptoms were compatible with those of a panic disorder with paroxysmal episodes of severe anxiety. Many years went by before the patient experienced symptoms more typical of pheochromocytoma such as sweating or palpitations. Pheochromocytoma is most frequently benign but malignancy which is defined as the presence of metastases in nonchromaffin tissue, may occur between 10 and $17 \%$ of cases (2). The size of $18 \mathrm{~cm}$ of our patient's pheochromocytoma is exceptional and supports the fact that the disease was present for a long time. Moreover, larger tumor size is an independent risk factor for malignant pheochromocytoma such as the case here (5). With the high morbidity and mortality associated with catecholamine-secreting tumors, early diagnosis is primordial and a high index of suspicion is needed in cases where symptoms are atypical.

Although there can be great similarities between the anxiety symptoms associated with pheochromocytoma and those that occur with a typical panic attack, they are not caused by the same biochemical mechanism; while the physiologic response to stress is secondary to a cortical impulse, in pheochromocytoma, it is caused by the circulating catecholamines that are completely independent of any CNS mechanism (6). Psychiatric disturbances in general are however not very well understood in pheochromocytoma. Apart from the direct effects of catecholamine hypersecretion, it is thought that cerebral blood pressure variations could also produce neuropsychiatric symptoms (7).

In our patient, the symptoms of panic attacks completely resolved after removal of the pheochromocytoma and the hepatic metastases as for patient 1 described from our cohort. Similarly, psychiatric disorder disappeared in patient 2 . It could be hypothesized that the very high levels of catecholamines may conduct to increased anxiety, although this correlation has not been clearly established. Pheochromocytoma is a rare disease and the prevalence of pheochromocytoma in individuals with anxiety disorder is unknown. However, the cases we presented here highlight the fact that pheochromocytoma should remain in the differential diagnosis of anxiety disorder especially when the response to appropriate psychiatric treatment is insufficient or absent.

\section{Declaration of interest}

The authors declare that there is no conflict of interest that could be perceived as prejudicing the impartiality of the research reported and they all fulfilled the ICMJE criteria.

\section{Funding}

This study was supported in part by a salary grant to I B from Fonds de Recherche du Québec-Santé.

\section{Patient consent}

Written informed consent for publication of their clinical details and/or clinical images was obtained from the patient.

\section{References}

1 Lenders JW, Duh QY, Eisenhofer G, Gimenez-Roqueplo AP, Grebe SK, Murad MH, Naruse M, Pacak K, Young WF Jr \& Endocrine Society. Pheochromocytoma and paraganglioma: an endocrine society clinical practice guideline. Journal of Clinical Endocrinology and Metabolism 201499 1915-1942. (https://doi.org/10.1210/ jc.2014-1498)

2 Plouin PF, Fitzgerald P, Rich T, Ayala-Ramirez M, Perrier ND, Baudin E \& Jimenez C. Metastatic pheochromocytoma and paraganglioma: focus on therapeutics. Hormone and Metabolic Research 201244 390-399. (https://doi. org/10.1055/s-0031-1299707)

3 Suzuki M, Konno C, Takahashi S \& Uchiyama M. Hidden harm. Lancet 2011377 874. (https://doi.org/10.1016/S0140-6736(10)61542-5)

4 Guerrero MA, Schreinemakers JM, Vriens MR, Suh I, Hwang J, Shen WT, Gosnell J, Clark OH \& Duh QY. Clinical spectrum of 
pheochromocytoma. Journal of the American College of Surgeons 2009 209 727-732. (https://doi.org/10.1016/j.jamcollsurg.2009.09.022)

5 Korevaar TI \& Grossman AB. Pheochromocytomas and paragangliomas: assessment of malignant potential. Endocrine 2011 40 354-365. (https://doi.org/10.1007/s12020-011-9545-3)

6 Kantorovich V, Eisenhofer G \& Pacak K. Pheochromocytoma: an endocrine stress mimicking disorder. Annals of the New York
Academy of Sciences 20081148 462-468. (https://doi.org/10.1196/ annals.1410.081)

7 Guerrieri M, Filipponi S, Arnaldi G, Giovagnetti M, Lezoche E, Mantero F \& Taccaliti A. Unusual clinical manifestation of pheochromocytoma in a MEN2A patient. Journal of Endocrinological Investigation 200225 53-57. (https://doi. org/10.1007/BF03343961)

Received in final form 25 February 2018 Accepted 9 March 2018 